\title{
CLUSTERING OF 2008 WEST BOHEMIAN SEISMIC SWARM MECHANISMS AND ITS POSSIBLE INTERPRETATION
}

\author{
Petr KOLÁ̌̌ * and Alena BOUŠKOVÁ
}

Institute of Geophysics, Czech Acad. Sci., Bočni II/ 1401, Prague 4, 14131, Czech Republic

*Corresponding author's e-mail: kolar@ig.cas.cz

\begin{tabular}{l}
\hline ARTICLE INFO \\
\hline Article history: \\
Received 15 September 2017 \\
Accepted 3 January 2018 \\
Available online 19 January 2018 \\
\hline Keywords: \\
West Bohemian earthquake swarm region \\
Source mechanism \\
Slip distribution \\
Finite seismic source model
\end{tabular}

\section{ABSTRACT}

Set of events from West Bohemian 2008 seismic swarm with known source mechanisms is processed. The events or their slips respectively are clustered into two groups: (i) principal events with slip laying in the main fault plane and (ii) complementary events deviating from that plane. From those slips we constructed image of slip distribution (a new way of data/slip presentation) and from slip distribution and variations we hypothesized about foci zone properties. Namely, we propose that western block is more rigid and compact; the eastern block appears to be constituted from several sub-blocks which can interact with each other during the swarm course. Our hypothesis is supported by similar image constructed from relative rupture velocities, which we consider as independent data. The proposed structural model agrees with the existence of the different observed types of source mechanisms.

\section{INTRODUCTION}

The detailed simulations of large earthquakes can be traced back already for decades - e.g. (Ihmlé and Ruegg, 1997) and the topic continuously remains to be of interest - e.g. (Jolivet et al., 2014). At the same time, the contemporary trend is to model moderated earthquakes in more detail. This is also the case of the presented study which deals with a set of earthquakes from a seismic swarm with magnitudes $\mathrm{M}_{\mathrm{L}}$ ranging from 0.1 to 3.8 . We clustered known source mechanisms according their slip directions; two general types of slip directions are considered: lying in the main fault plane and significantly deviating ones. From clustered slips we constructed hypothetical model of spatial slip distribution and finally we hypothesize about focal zone geological settings.

The magnitude range of events investigated in detail, especially its lower limit, is definitely conditioned by a development of observation technique as only high quality data from the sufficient number of stations can be subject of our studies. This is also the case of data from the West Bohemian / Vogtland region (Czech Republic / Germany; Fig. 1) which we processed. The West Bohemian region is known for reoccurrence of aperiodic seismic swarms which clustered events in space and time. These phenomenon was and is subject of various studies starting from fundamental seismic bulletin assembly to general reviews or highly specialized studies - see e.g. special volumes of Studia Geophysica at Geodeatica (2008; 2009) and further (Kolář and Růžek, 2012; Chum et al., 2012; Růžek and Horálek, 2013; Fischer et al., 2014; Čermáková and Horálek, 2015; Kolář, 2015; Kolář and Růžek, 2015; Vavryčuk et al., 2017).
West Bohemia seismoactive region is situated close to the contact of three main geological units: Saxothuringian, Teplá-Barrandian and Moldanubian (Babuška et al., 2007; Babuška et al., 2010). It displays complex tectonic as well as geological structure. Quaternary volcanoes, Komorní Hůrka, Železná Hůrka and the newly described Mýtina maar (Mrlina et al., 2009), all of them with the age less than $0.8 \mathrm{Ma}$, together with deep originated $\mathrm{CO}_{2}$ emanations, indicate recent geodynamic activity of the region (Geissler et al., 2005; Babuška et al., 2007). At the intersection of two fault systems: Eger Rift trending ENE-WSW and deep Mariánské Lázně fault trending NNW-SSE, originated Cenozoic Cheb Basin. Moreover, N-S and E-W trending faults as described by (Bankwitz et al., 2003) conduce to weakening of Earth's crust. The northern part of Cheb Basin with Variscan Smrčiny granitoid massive and mica schists of Saxothuringian Krušné hory Crystaline Complex in its bedrock is located in the centre of the seismically active area.

Principal part of West Bohemian events is situated close the east margin of the Cheb Basin along almost vertical fault plane oriented approximately in N-S direction (Čermáková and Horálek, 2015). But not all the events occurred on this fault. There is a group of events which slips deviate from this principal plane. This phenomenon was referred many times e.g. (Horálek et al., 2000; Horálek et al., 2002) and recently by (Vavryčuk et al., 2017). In the paper we explore events slip orinetation, their mutual positon and consequently speculate about foci zone geological structure (supporting geological works are referred). 


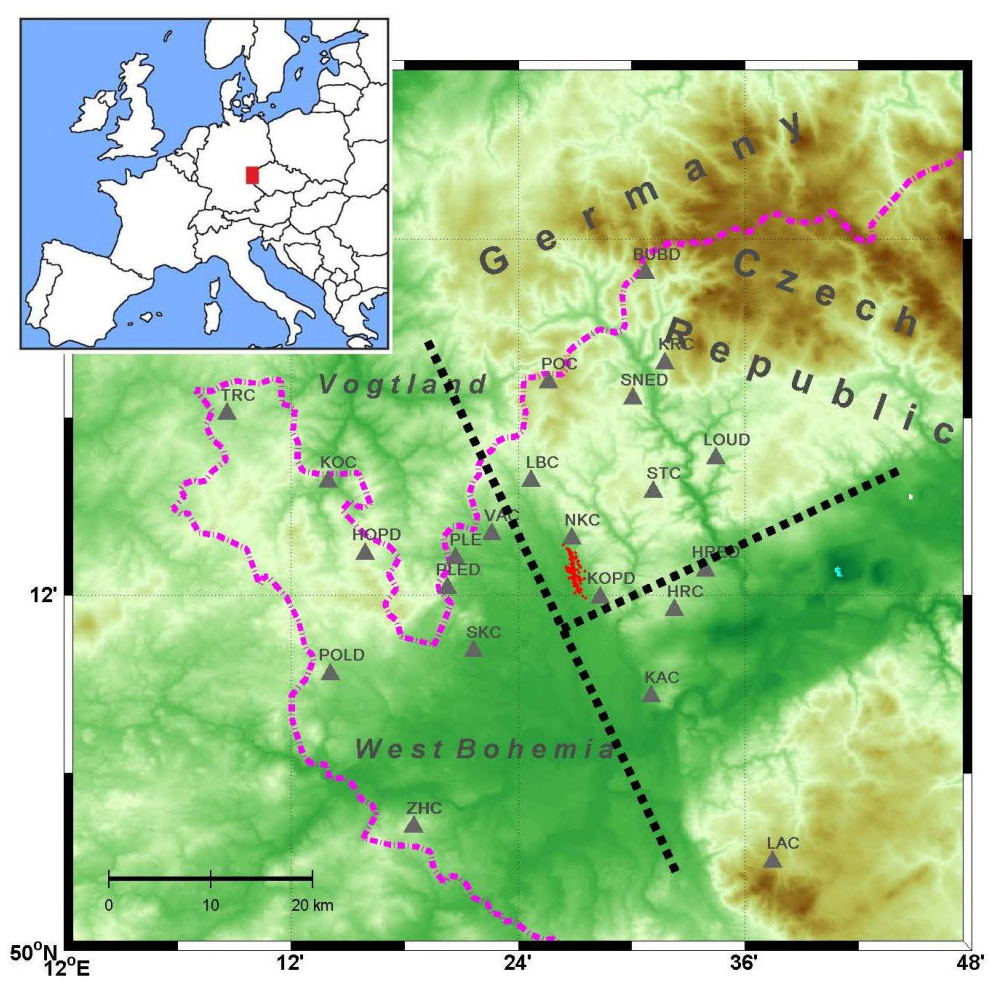

Fig. 1 Map of West Bohemian region. A standard topographic map of the area, state border (dashed line), stations used in the present study (triangles) and epicentres of the investigated events (cloud of red crosses southerly from station Nový Kostel - NKC) are plotted. Two principal fault system directions: Mariánské Lázně fault in direction NNW-SSE-and approximately perpendicular Eger rift (direction ENE-WSW) are indicated by black doted lines.

\section{DATA}

We processed data from the pronounced 2008 West Bohemian seismic swarm. This swarm lasted from the beginning of October to the end of December 2008 with few aftermaths at the beginning of 2009. More than 4600 events $\left(\mathrm{M}_{\mathrm{L}}>0\right)$ with maximum magnitude $\mathrm{M}_{\mathrm{Lmax}}=4.0$ were recorded (Fischer et al., 2010). Seismic activity of the region is continuously monitored by WEBNET seismic network (wwwWEBNET, n.d.; wwwFDSN: WB:, n.d.). This network was established in 1985, when two first digital stations were deployed during an ongoing pronounced seismic swarm. Since then the network is more or less continuously developed and upgraded. In 2008 year WEBNET operated 22 stations ${ }^{1}$, which is sufficiently high number to perform detailed studies over observed data.

The time and spatial distribution of 2008 swarm as well as the distribution of selected events are given in Figure 2. Generally, the swarm activity started in the south in the depth about $10 \mathrm{~km}$ and spread upwards and to the north; the most of energy was released in earlier phases of the swarm, when most of the observed events also occurred.

In our work we processed only events with determined source mechanism, i.e. events which were recorded and interpreted reliably enough on the majority of the network stations, which was the most limiting factor for processed events preselection. The final set of investigated events consists of 454 selected events $\left(M_{L} 0.1-3.8\right)$ with available locations, stable source mechanisms with known preferred fault plane orientation (Vavryčuk et al., 2013) and in addition with finite circular source models (Kolář, 2015; Kolář and Růžek, 2015), which parameters were interpreted lately.

\section{DATA ANALYSIS}

Firstly, we studied the slip distribution during the swarm. To create a model of a detailed slip distribution in the hypocentral zone, we combine precise event locations (Vavryčuk et al., 2013) with estimated accuracy better than $20 \mathrm{~m}$ (Bouchaala et al., 2013) and slip derived from source mechanisms determined for the set of selected events also by (Vavryčuk et al., 2013). Further, finite source relative rupture velocities determined by (Kolář, 2015; Kolár and Růžek, 2015) are used to support observed structures. Those values come from modelling of finite seismic source by Stopping phases method.

Source mechanisms for selected events from 2008 year swarm were determined by (Vavryčuk et al., 2013); moment tensor formalism was used in this study. It is a well-known fact that moment tensor can be decomposed into two fully equivalent fault plane solutions, but (Vavryčuk et al., 2013) has developed

${ }^{1}$ Remember, that in 2000 year, when previous pronounced seismic swarm occurred, the network operated only 8 permanent and 4-6 temporary stations. 

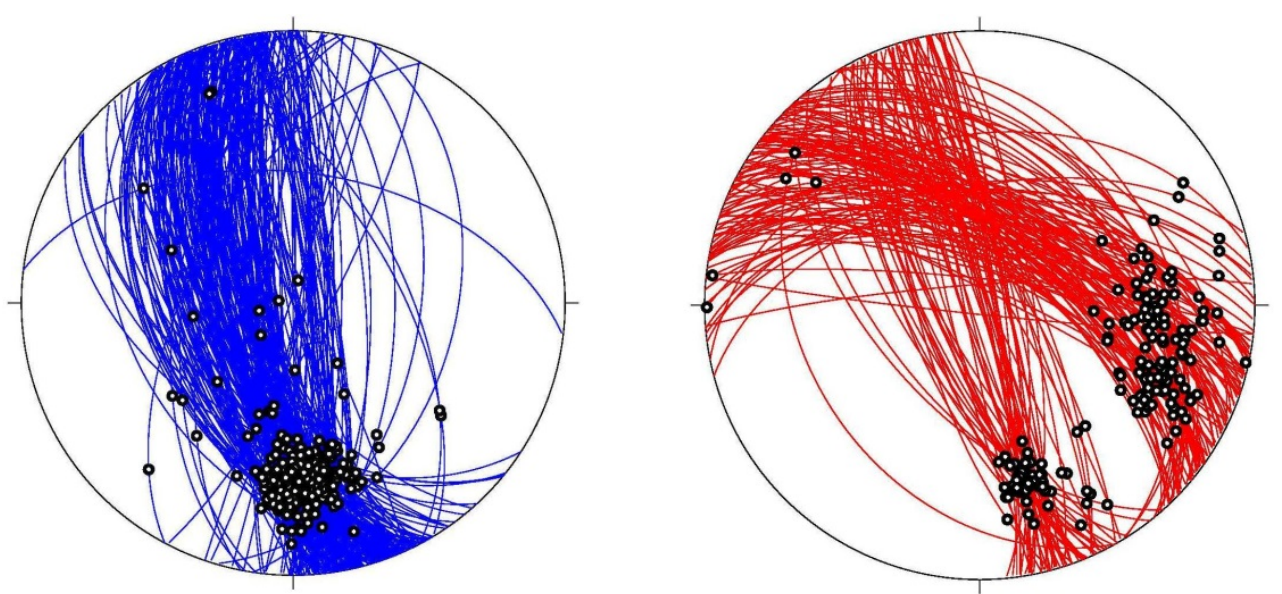

Fig. 3 Nodal lines of preferred fault plane solutions. Left panel - events with "principal" orientation; right panel - "complementary" orientations (instead of classical "beach ball" only preferred solutions or corresponding lines, respectively, are plotted). The projection of the slip vectors are marked by 'o' symbols.

a method that enables to select more probable fault plane orientation with respect to the orientation of principal stress in the region ${ }^{2}$. Next step consists of clustering of the processed events by their slip orientation. There is no doubt, that the prevailing slip of West Bohemian earthquakes occurs on sub-vertical main fault oriented in almost N-S direction; the western block is moving to the south and down or vice versa for the eastern block. The set of 2008 processed events (454 selected events with known preferred source mechanisms) were clustered into two sub-sets: (i) events which obviously occurred on the main fault (i.e. strikes of these events oscillate round the value $180^{\circ}$ and their slips point down and to the south); this cluster contains 277 events. (ii) Complementary events with strike roughly oriented in WNW-ESE direction and their slips pointing to the east -177 events. We arbitrary chose the deviation limit from the main fault to be $20^{\circ}$. The orientation of fault planes for both clusters is shown in Figure 3. The slip vectors are calculated using formula [4.83] given by (Aki and Richards, 1980) or [4.88] in (Aki and Richards, 2009), respectively, which enables to express slip $\overrightarrow{\mathbf{u}}$ from the known fault plane orientation (i.e. from strike $\Phi_{S}$, dip $\delta$ and rake $\lambda$ )

$\overrightarrow{\mathbf{u}}=\bar{u}\left(\cos \lambda \cos \Phi_{s}+\cos \delta \sin \lambda \sin \Phi_{s}\right) \overrightarrow{\mathbf{x}}+$

$+\bar{u}\left(\cos \lambda \sin \Phi_{s}-\cos \delta \sin \lambda \cos \Phi_{s}\right) \overrightarrow{\mathbf{y}}-\bar{u} \cos \lambda \sin \delta \overrightarrow{\mathbf{z}}$

where the vectors $\overrightarrow{\mathbf{x}}, \overrightarrow{\mathbf{y}}, \overrightarrow{\mathbf{z}}$ are oriented in direction $N$, $E$, down and $\overrightarrow{\mathbf{u}}$ is slip size. Slips of processed events determined by the equation are presented as 3D plot in Figures $4 \mathrm{a}, \mathrm{b}$ and as 2D slice in Figure 4c. Size of the slip vector is proportional to the event magnitude according to the formula for average slip slip $=c \frac{M_{0}}{\mu \pi r^{2}}$

where $M_{0}$ is the scalar seismic moment and $r$ is the estimated source radius, $\mu$ is the rigidity and $c$ is a constant - see e.g. (Stein and Wysession, 2003); as we are interested only in the relative size of the slip, the constants $\mu$ and $c$ play no role. The scalar seismic moment $M_{0}$ in $[\mathrm{Nm}]$ is given as

$\log M_{0}=1.5 M_{L}+11.3$

which is an empirical relation between $M_{0}$ and magnitude $M_{L}$ given by (Hanks and Kanamori, 1979) modified for the region by (Horálek et al., 2002; Hainzl and Fischer, 2002). The circular source radius $r$ in $[\mathrm{m}]$ is estimated by relation

$r=30 \times 10^{\left(0.33 M_{L}\right)}$,

given by (Fischer and Horálek, 2005) and confirmed by (Koláŕ and Růžek, 2012; Kolář, 2015; Kolář and Růžek, 2015). Radiuses of processed event sources vary from about 30 to $550 \mathrm{~m}$.

For a while, the principal and complementary events are processed separately. To be able to think of slip as integral and continuous phenomenon we transformed individual principal slips into the slip "flow" which is given in Figure 5. This transformation uses a MATLAB function 'streamslice' which transforms vectors (i.e. slip vectors in our case) into lines of their directions. The background idea of such approach is to treat the slip on the fault as a continuous "flow" value, which is in graphical form represented by slip-lines. The slips of individual events are computed with use of (1); 'streamslice' function input data are used interpolated (inside the investigated area) or extrapolated (in outer area) slip values, respectively. The linear interpolation was

\footnotetext{
${ }^{2}$ The reliability of preferred source orientations was recently also confirmed by (Kolár, 2015) where the complementary mechanisms were optionally tested when determining parameters of finite seismic source models. Only few (less than $4 \%$ ) of preferred orientations had to be corrected.
} 


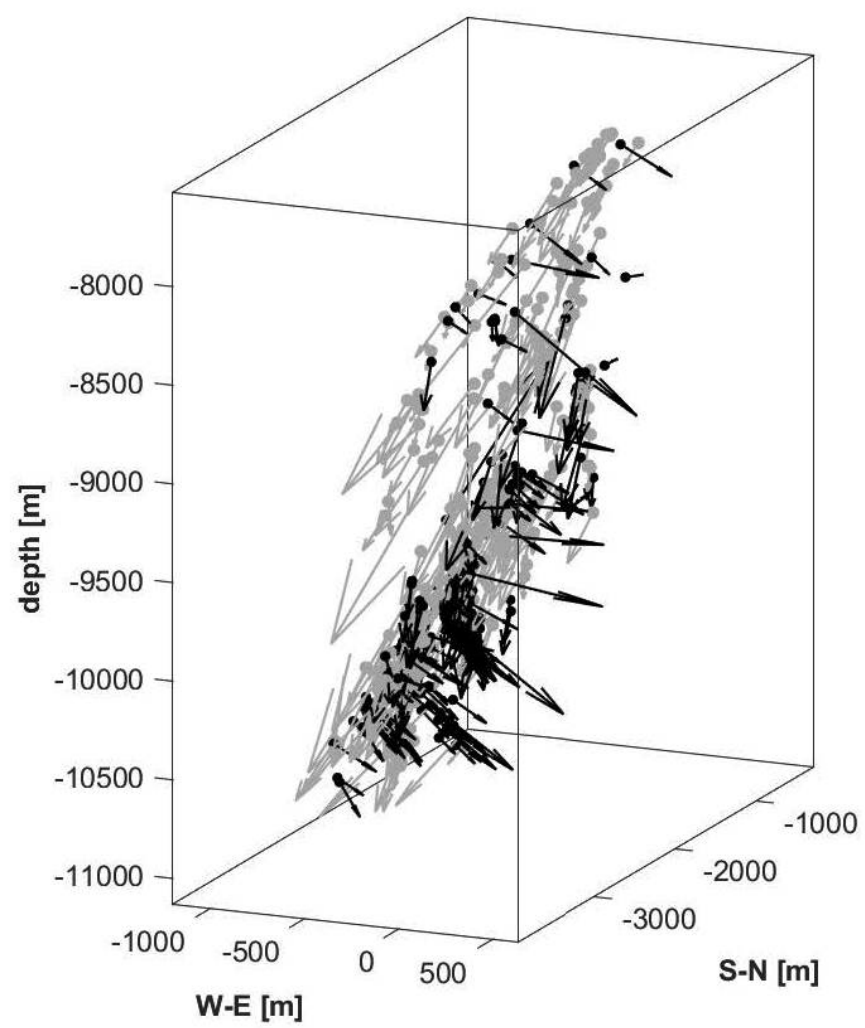

Fig. 4a Event slips seen from SSE and elevation $15^{\circ}$. Slips of "principal" events (lying approximately in the principal fault plane) are marked by grey colour, the "complementary" ones (deviating from the fault plane) then by black; including corresponding hypocentres. The coordinate origin is in station Nový Kostel (NKC); slip vector size is proportional to event magnitude according eq. (2).

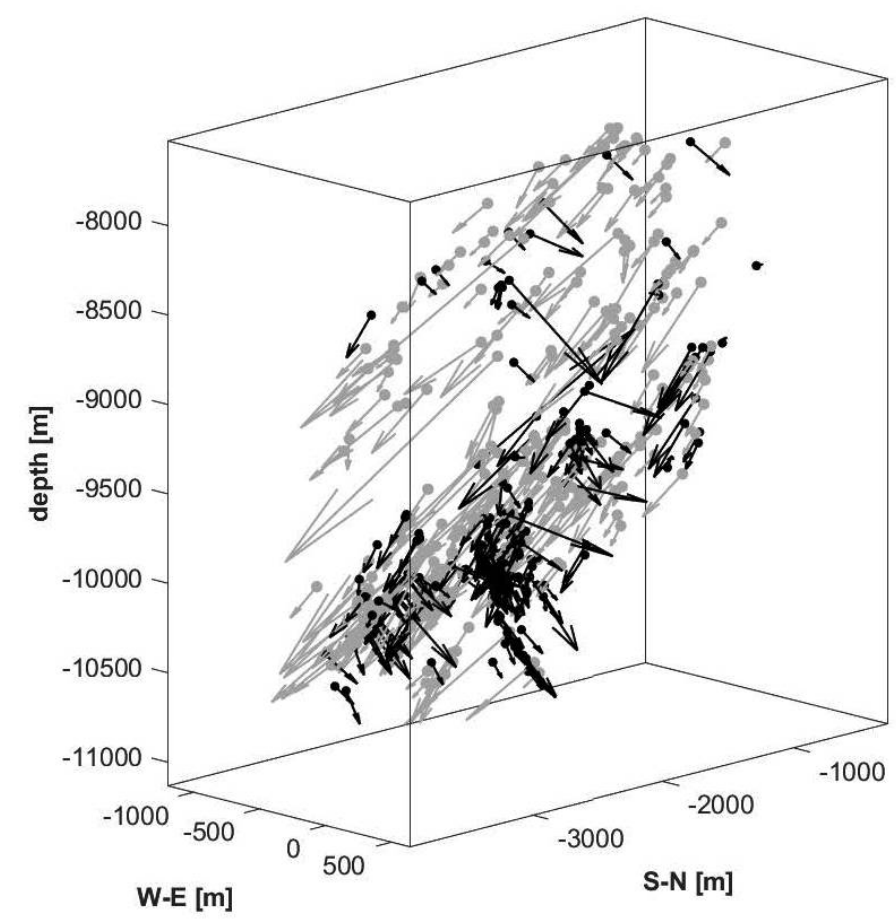

Fig. 4b The same as in Figure 4a, but seen from SE. The figure is intended to help to demonstrate spatial distribution of the investigated events (together with Fig. 4a). 


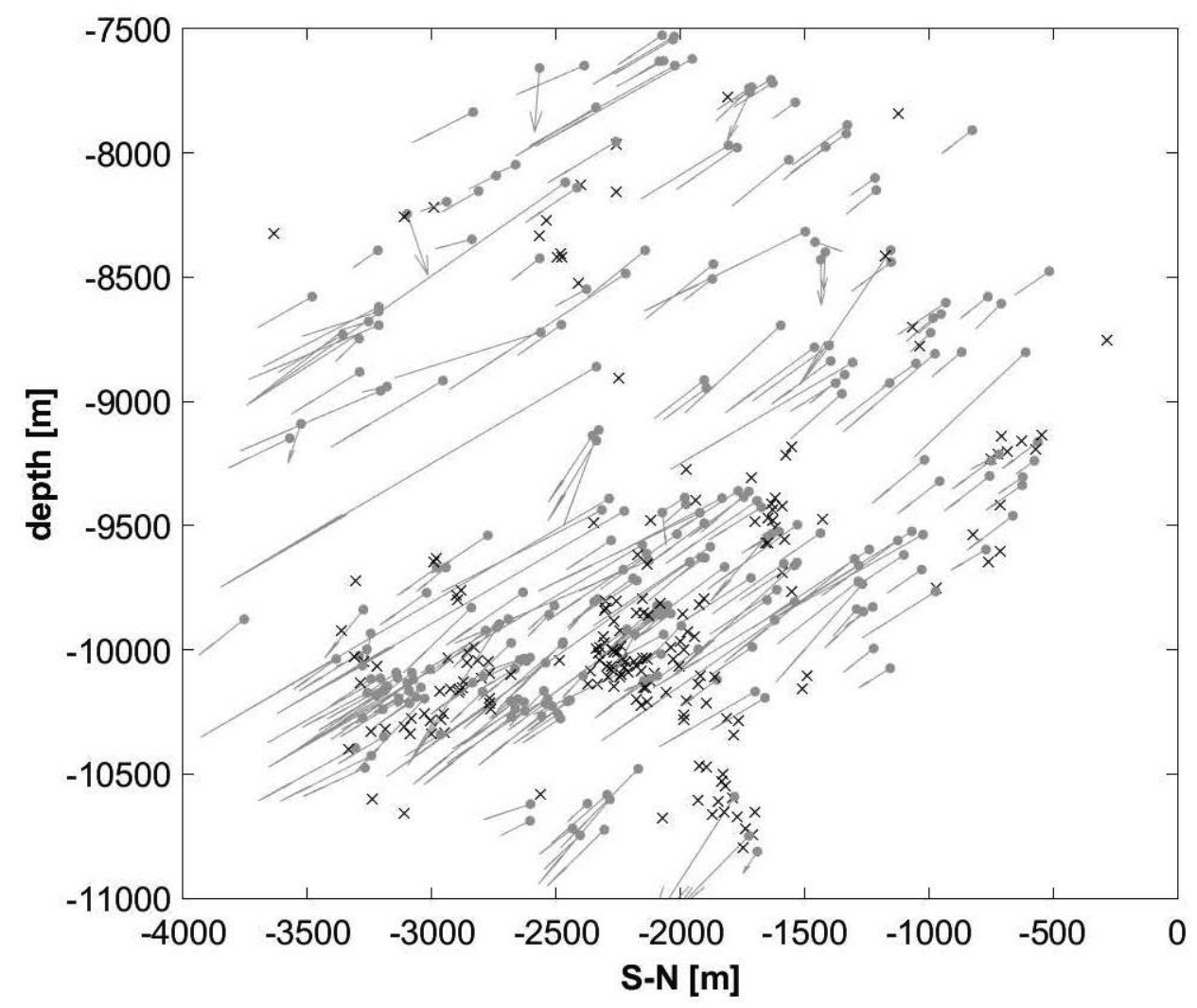

Fig. 4c 2D vertical N-S slice of slip distribution. The used projection is close to the best fitting plane; to keep the figure clear only principal slips are plotted, for complementary events only foci are marked (' $x$ ').

used, while extrapolation sets the value to the nearest point value as the other ways result into roughly unrealistic behavior. The created slip flow image is a nonstandard way of data representation. It is not purely physical approach (e.g. slip is here supposed occurred in a point instead of finite source, the time scale is neglected, the construction is based on interpolated values, etc.), but we believe that its use is justified by the information which can be retrieved from the final image - see below. In the created image of slip it can be seen zones/lines, where slip-lines change abruptly their density and/or direction. We consider these lines as potential candidate of boundaries in the medium. A synthetic example of flow construction from a vector field is given in Figure 6; it can be helpful to understand way of slip flow construction. The presented slip-lines are sensitive to interpreted vector directions, while the role of their size is supressed. From this point of view our slip representation is the opposite to the common way of earthquake slip inversion - e.g. Figure 7 in work of (Liu and Archuleta, 2004), where izolines of the same slip values in the source are given with no regards to their directions. The similar approach was used also for West Bohemian events in (Koláŕ et al., 2011).

In the same way as for the principal slip we constructed spatial slip variation based on events with complementary slip orientation. The results are combined with principal slip in Figure 7; to distinguish these two movements of different directions, different graphical representations are used: (i) the principal event slip is plotted as a vector flow (same as in Figure 5), while (ii) size of complementary slip is represented by coloured scale. Boundaries interpreted from the appeared structures are indicated too. These boundaries are interpreted manually and are supposed to separate areas of the same or similar slip behaviour. We have made several attempts to discover the boundaries in a more exact way (e.g. with some "contour" functions) - Figure 8, but the results were not fully stable, namely the small details in the middle of the area. Therefore we preferred to interpret boundaries manually. N.B. that principal boundary shape is preserved in both methods. However also computed version of interpretation can be objected for the same points as the manual one, e.g. low number of data in the borders, etc.

\section{SLIP IMAGE INTERPRETATIONS AND DISCUSSION}

From the above presented clustering of events mechanisms follows that events occur either on principal fault or on complementary one(s). Neither image of principal slip nor of complementary one are homogeneous, but some patterns can be observed this structures are interpreted below. There is not known any complementary event with slip pointing westerly, but all the slips point easterly. All the complementary events occur eastwardly from the main fault: the average distance of complementary events from the fault is $10+/-8 \mathrm{~m}$, if the fault defined as best fitting plane of all processed events. When main fault is defined as the best fitting plane of principal events only, the average distance increases 


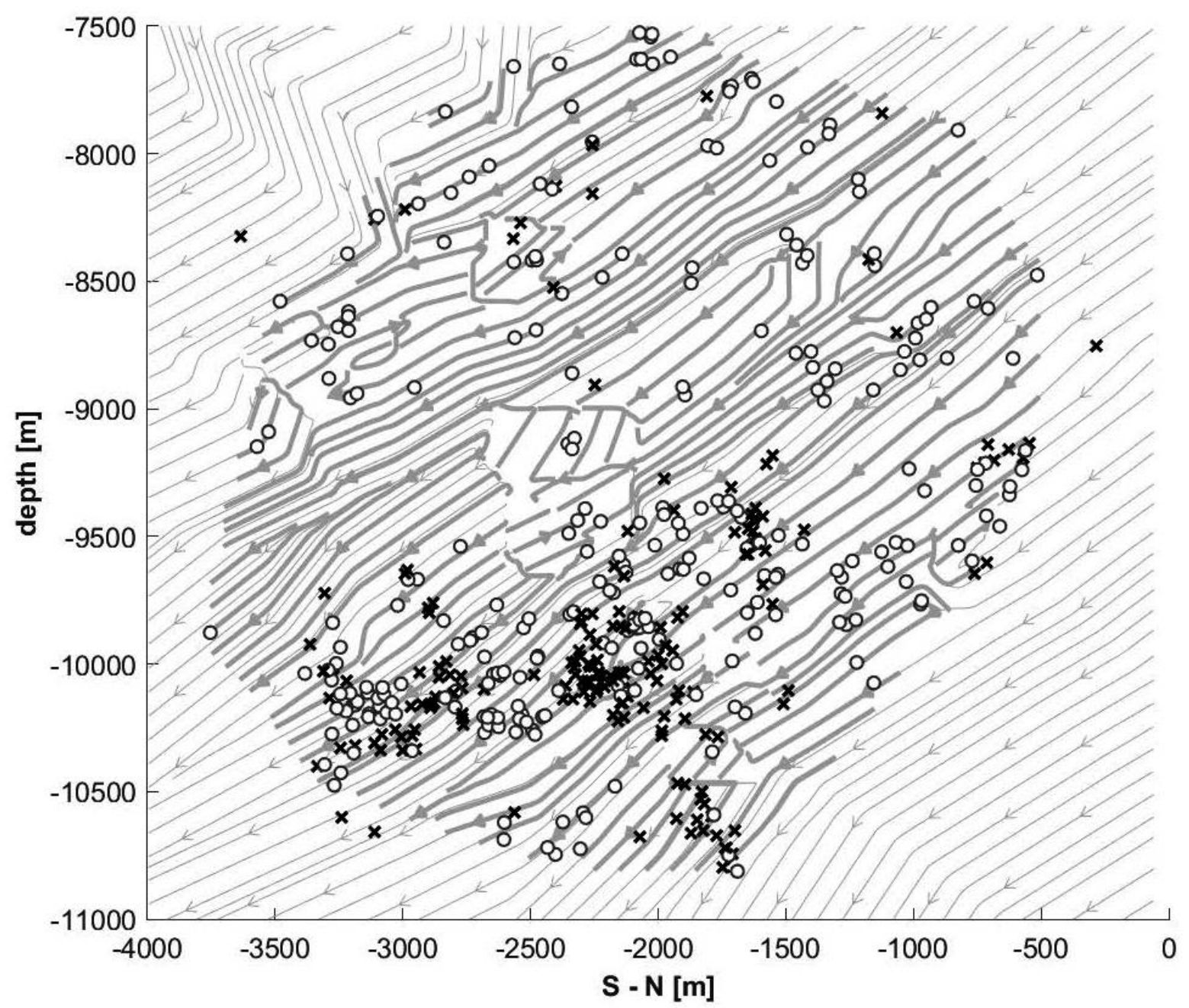

Fig. 5 2D vertical N-S slip-flow for principal events. The flow is constructed from individual slips of principal events - see the text. The hypocentres of theses principal events are marked by 'o', the interpolated flow values are marked by thick lines, the extrapolated values by thin ones. The positions of complementary events are marked by black ' $\mathrm{x}$ '. The vertical slice is of N-S orientation, seen from the east, coordinates origin is in $\mathrm{NKC}$ station.

to $15+/-8 \mathrm{~m}$. And when the reference plane is defined by 6 principal events closest to the investigated complementary event the average value increases up to $36+/-9 \mathrm{~m}$. We conclude that the systematic eastern shift of complementary events is obvious.

We interpret the presented fact in following way: western part of investigated hypocentral zone appears to be more compact and homogeneous. The eastern part then seems to be composed of several sub-rectangular blocks with the edge size of about 0.5-1 km (i.e. size of structures observed in Figure 7). On the boundaries of these sub-blocks occur the complementary events. Those (eastern) blocks may slightly mutually rotate, to be temporary twisted or locked during the swarm course. The fault area which can be modelled in detail is limited by distribution of investigated hypocentres; its size is about $4 \times 4 \mathrm{~km}$. On the basis of our data, we cannot speculate about the length of theses blocks in eastern direction, as they are not "lightened" by events in this direction.

From the geological point of view, we can consider about more compatible western block composed e.g. by granite of Smrčiny massive as it is mentioned e.g. in review paper (Babuška et al, 2015), Fig. 5 of the quoted work. This model was created using gravimetric data published by (Hecht et al., 1997); even though they propose its bottom in only 5 $\mathrm{km}$ depth, being above hypocentres of considered events. The eastern block possesses more heterogeneous structure and seems to be less compact; it can be composed of e.g. sub-cuboids with a possibility of their mutual partial sliding, rotations or torsions. Such physical behaviour argues for its different composition e.g. from phylites. The presented blocks hypothesis can explain the existence of events of two different types of source mechanisms and enables to explain observed motions in the foci zone. In addition, it corresponds with an available regional geological model: fault plain active during 2008 swarm belongs to N-S fault system visible as Plesná fault in Cheb Basin south of Nový Kostel, perhaps Nový Kostel-Počátky-Zwota zone (Bankwitz et al., 2003). This fault mapped by seismic swarms plane intersects in Nový Kostel area NNW-SSE trending Mariánské Lázně fault, which forms eastern margin of Cheb Basin (Fig. 1). Cenozoic Cheb Basin 

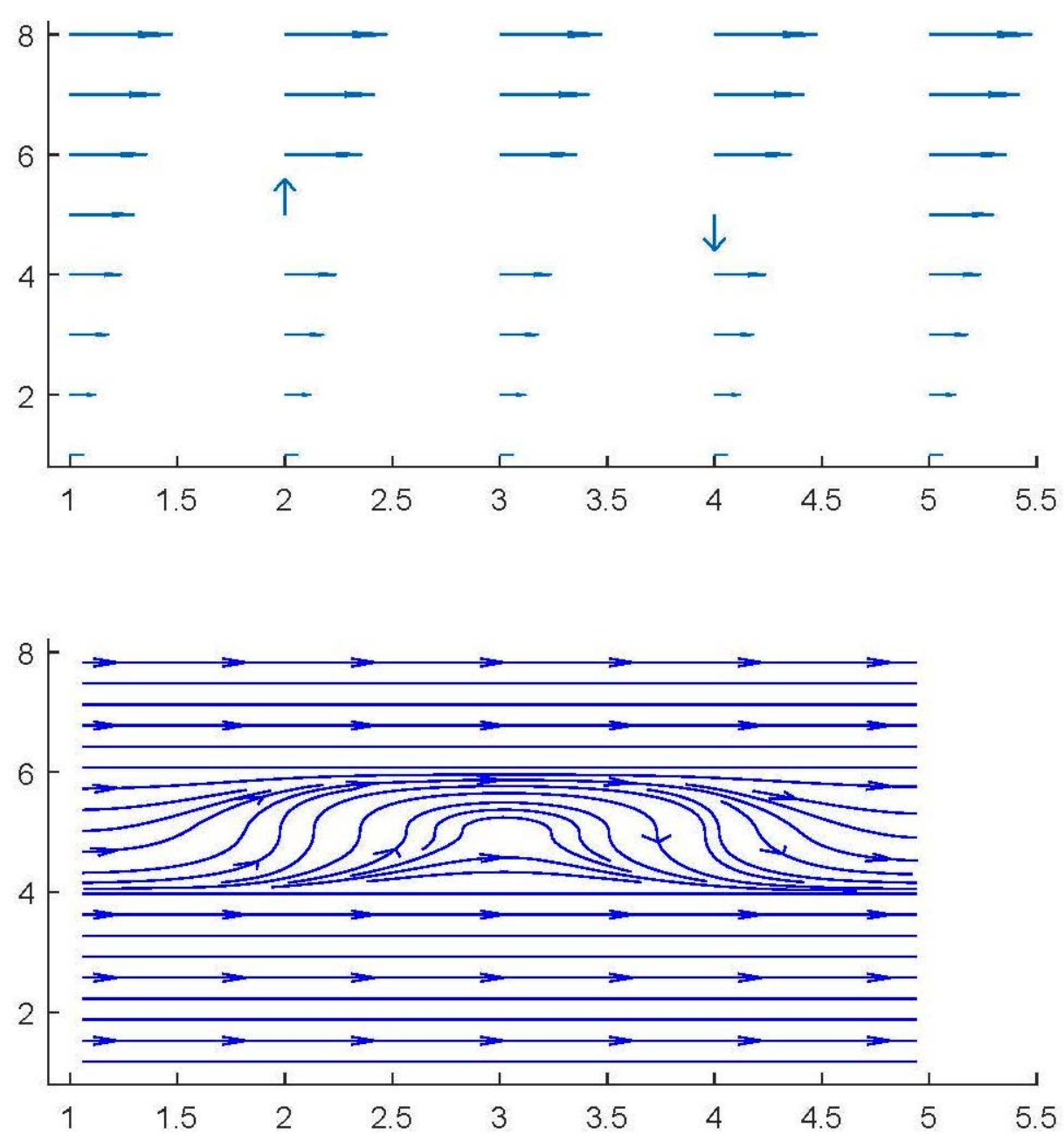

Fig. 6 Synthetic example of vector flow. From the (synthetic) vector field (upper) is crated vector flow (lower). The vector field is of homogeneous horizontal direction but for two vertical vectors (of opposite orientation). The flow lines shows sensitivity to changes of vector directions, while the vector size has practically no influence.

with bedrock formed by Smrčinský granite is located westward of Mariánské Lázně fault. Eastward of the fault, there are phylites, mica-schists and gneisses of Svatava crystaline. In addition, Mariánské Lázně fault is in this northern part broken by younger transverse faults. We can assume, that these or similar faults can lead to breaking up the space between the faults to relatively small blocks. Such small structures in the depth of about $10 \mathrm{~km}$ can be at least speculated thanks to the methodology used in the presented study.

It is obvious, that the reliability of interpreted slip distribution is not homogeneous over the observed fault plane as the spatial distribution of the processed events is also irregular. Especially towards the area borders, the slip image may be rather doubtful. On the other hand, the used data, namely relative events location, are determined with high precision. The events mechanisms of investigated events may also suffer from some level of uncertainty (let us estimate the uncertainty in order of degrees, let say $10^{\circ}$ at maximum). Several ambiguous events (from point of view of our clustering) lay in depth about $9.5 \mathrm{~km}$ in northern part of investigated area. Even if we admit that those events can be wrongly clustered, it does not change the general slip image. Our clustering is rather rough, we sort the events only into two groups and we therefore expect that the distribution is fairly stable. In addition, the final image (Fig. 7), which is used to formulate the conclusions, is based on smoothed and averaged data. Therefore some possible individual misinterpretation cannot dramatically change the final view. Also used rough clustering into two groups only contributes to the stability of the results.

What definitely remains a limiting factor of our approach is the fact that only small fraction of swarm events is investigated, whereas the crucial restriction is knowledge of preferred fault plane solution. However as it follows from histograms in Figure 9, at least for magnitude $\mathrm{M}_{\mathrm{L}}$ range 1.1-2.5, the selected/processed events can be considered as a proportional sample of the whole swarm. Also the block boundaries interpretation inevitably possesses subjective features. In addition, should the number of processed events increase the interpreted image can possibly be corrected. But an increase of the known fault plane solutions cannot be expected, unless new reinterpretation (possibly with a new methodology) is 


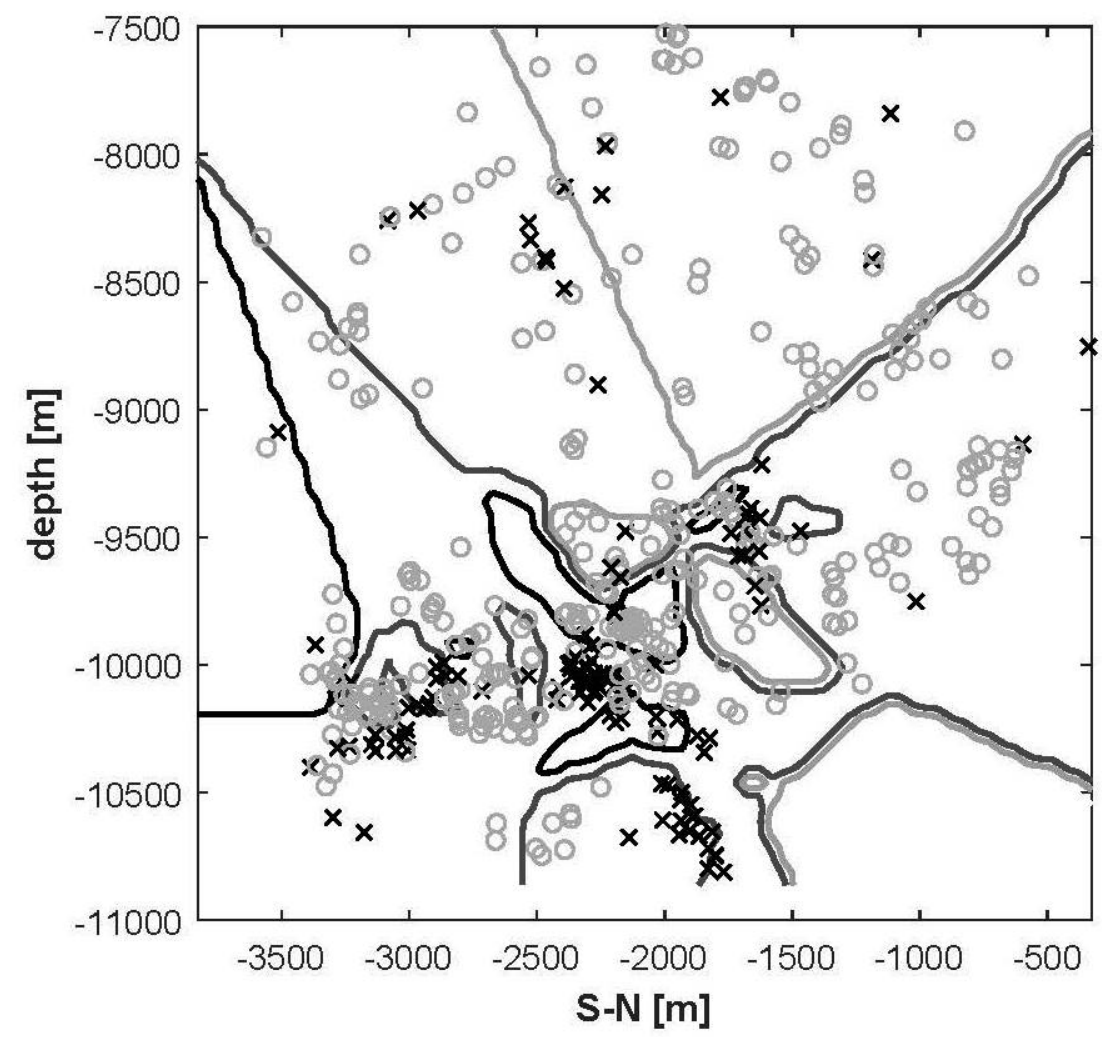

Fig. 8 Attempt of automatically boundaries search. Result of automatically boundaries interpretation, here from complementary slips; as the results were rather unstable, we prefer manual interpretation (c.f. Fig. 7), however general trend of boundaries are similar. The position of principal ('o') and complementary ('x') events are plotted too.

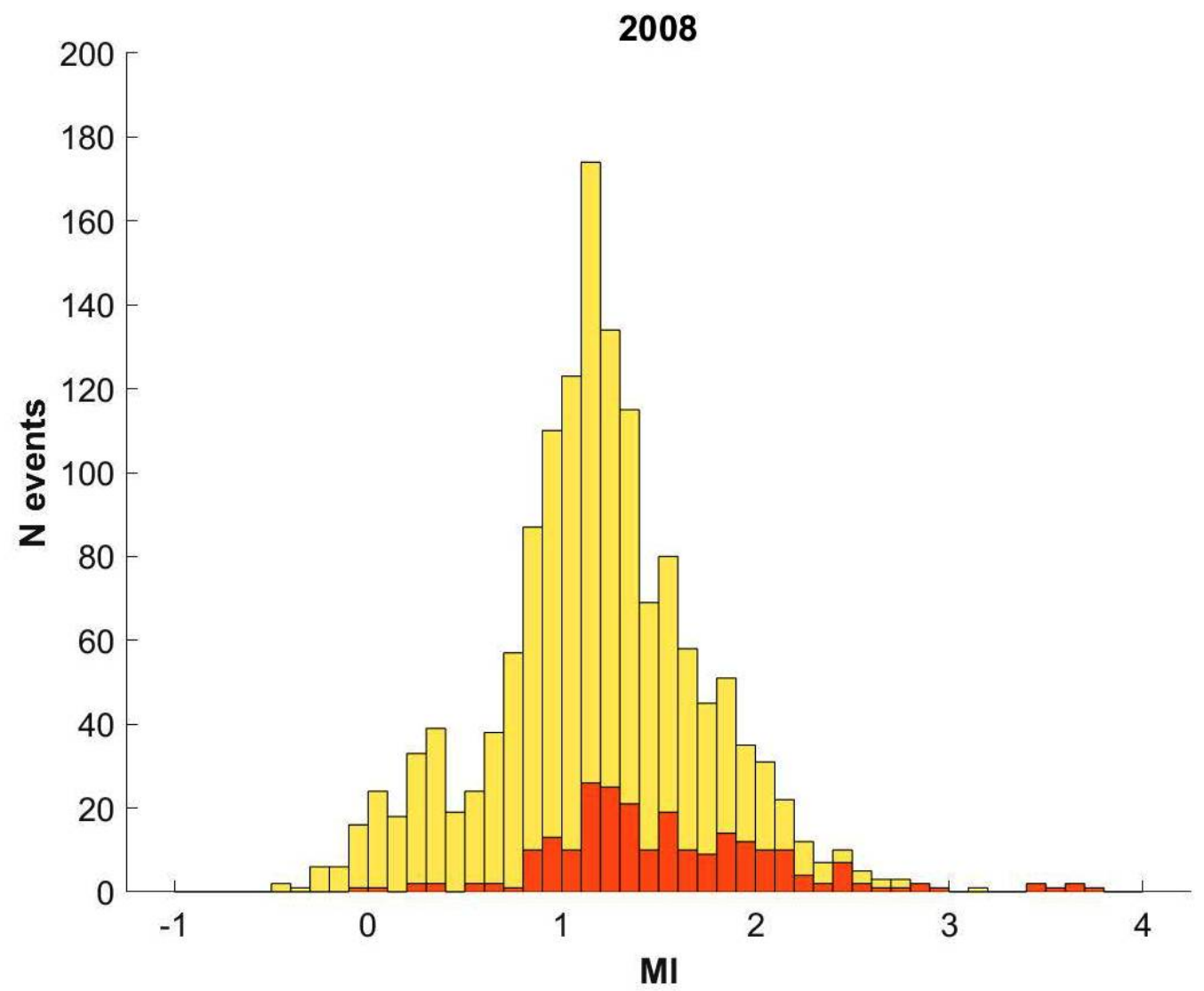

Fig. 9 Magnitude-frequency histograms. All the 2008 swarm events (yellow) occurring during the first two swarm phases (i.e. events marked by yellow in Figure 2); selected events processed in the study (red). It can be concluded, that at least for magnitude range $\mathrm{M}_{1}=1.1-2.5$ the selected events can be considered as a proportional sample of all events. 


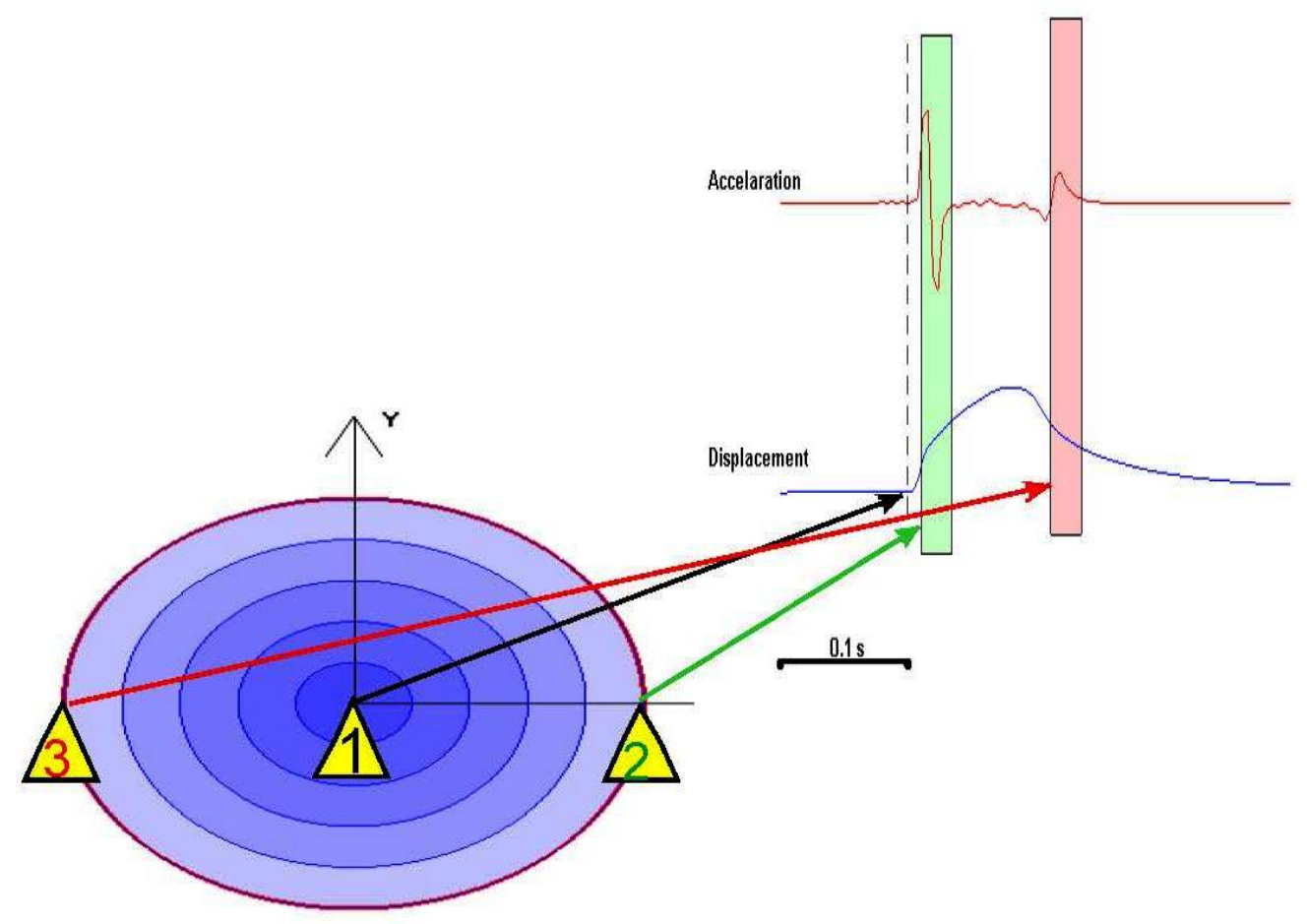

Fig. 10 Schema of Stopping phases generation. A finite circular source seen from a seismic station (here, a circular source is symbolically distorted into ellipse by perspective). Onset of the (synthetic) signal comes at the station from the nucleation centre (marked by 1). When the rupture process stops at the source boundary, it is manifested in signal as an abrupt change of the amplitude value - the onset of the first stopping phase corresponds to the radiation from the point 2 (the source point nearest to the station). Radiation from the farthest point of the source (marked by 3 ) is then manifested in seismogram as arrival of the second stopping phase. The rest of the signal - displacement after the second stopping phase corresponds to the healing process of the event according to the M-model by (Boatwright, 1980). The manifestation of stopping phases, determined with use of their mutual correlation, is obvious. The observed arrival times of stopping phases from several stations can then be inverted into parameters of finite seismic source model.

The presented synthetic seismogram was constructed as a sum of elementary seismograms from point sub-sources distributed on the fractured area of the finite source; corresponding acceleration is plotted above displacement signal - adopted from (Koláŕ, 2013).

performed $^{3}$. On the other hand, even with restricted number of events we are able to design a medium model of foci area with some indication of its geological properties. And this model can be tested in the future by the (intended) processing of data from consecutive swarms.

As a support for presented slip image or consecutive hypotheses respectively, we propose image of rupture velocity distribution. The relative finite source rupture velocities are taken from (Koláŕ, 2015; Kolář and Růžek, 2015); they were determined by Stopping phases method. The method is based on theoretical work of (Bernard and Madariaga, 1984) and was brought into practical use by (Imanishi and Takeo, 1998; Imanishi and Takeo, 2002); see Figure 10. The method enables to determine parameters of finite circular seismic source model, namely source radius and rupture velocity. We applied the method on the set of selected events from the West Bohemian swarm 2008 (Kolář, 2015; Kolář and
Růžek, 2015). As the Stopping phases method required knowledge of the event location and source mechanisms the investigated set is practically identical with event set from the present study. We constructed image of rupture velocity in the same way as for the slip while the rupture velocity values are considered to be another (independent) spatial parameter. The relative rupture velocities of complementary events are plotted on background of principal slip flow in Figure 11.

The relative rupture velocity $v_{r r}$ is conventionally given as

$v_{r}=v_{r r} v_{S}$

where $v_{r}$ is rupture velocity and $v_{S}$ is $\mathrm{S}$ wave velocity; typically given value of $v_{r r}$ is $0.9 v_{S}$. In (Koláŕ, 2015) relative rupture velocity was determined, but as it follows from (5) its variation can be equivalently interpreted also as a variation of $\mathrm{S}$ wave velocity and

\footnotetext{
${ }^{3}$ We e.g. made an attempt of extended number of investigated events on the basis of similar maximal observed amplitude ratios on selected stations (for the supplementary events would be enough to know only their cluster - principal vs. complementary - the source mechanism itself can remain unknown). Unfortunately, such approach did not yield reasonable results and we did not succeed to extend set of processed events.
} 
even the effect can be a mix of variation of both parameters $\left(v_{r r}\right.$ and $\left.v_{S}\right)$. Similarly as in the slip image (Fig. 7), we interpret possible structural boundaries at points where the both investigated values (slip, velocity variations) exhibit significant changes or discontinuities. These boundaries qualitatively agree with boundaries founded in slip image (Fig. 7).

An alternative $3 \mathrm{D}$ view of the relative rupture velocity distribution is presented in Figure 12. Also here similar boundaries can be interpreted. The undulation of rupture velocity izolines displayed in Figure 12a can be a "projection" of block structure suggested above, but distorted by 3D graphical representation when smoothing and rounding must be applied. If $\mathrm{v}_{\mathrm{rr}}$ values only for stronger complementary events are considered $\left(\mathrm{M}_{\mathrm{L}}>0.8\right)$, it can be seen a more complex structure: sub-vertical and sub-horizontal boundaries can be interpreted, a slight declination of the lower $\mathrm{S}$ waves velocity structure to east with decreasing depth can be also seen. The decomposition of the higher velocity structure (red colour) into smaller parts/blocks is roughly indicated.

Note, that there are some recent structural studies for the area under the interest. For example (Růžek and Horálek, 2013) propose an up-doming structure in the foci area. Unfortunately, the image of the structure is not detailed enough as the applied tomography method used 2x2x2 km boxes. (Mousavi et al., 2015) interpret velocity variation in the region as an intrusive body and potential fluid pathway (Fig. 10 of quoted work); some spatial anomalies are indicated also in (Novotný et al., 2016). Alexandrakis et al. (2014) studied $\mathrm{v}_{\mathrm{P}} / \mathrm{v}_{\mathrm{S}}$ ratio for swarm 2008, however their medium model range from the foci zone to the surface. Bachura and Fischer (2016) studied $v_{\mathrm{P}} / \mathrm{v}_{\mathrm{S}}$ ratio for foci zone, but for 2014 swarm. This work is focused on (possible) role of fluids during swarm course, while our study is rather oriented on description of pre-existing structures in the zone. Generally, we understand those results as an alternative interpretation of the observed data and complexity of studied phenomenon rather than contradicting hypothesis.

\section{CONCLUSION}

In our study we clustered events by the direction of their slip into principal and complementary sets: slips of principal events lie on the main fault, the complementary ones deviate from it significantly. We constructed slip flow image - a new way of data representation - which can yields information about structure in foci zone. From slip distribution and variations we hypothesised about physical properties of blocks constituting the main swarm fault as well as about their more subtle structure: The western block exhibits more compact and homogeneous properties; it can be constructed e.g. from granite. The eastern block shows a more detailed structure - it is supposed to be composed of congregation of more or less rectangular sub-blocks which are supposed to be in dynamic relation in the swarm course; it can be composed e.g. from phylites. The constructed slip image qualitatively corresponds with similar image constructed for rupture velocity, or S wave velocity distribution, respectively, which we consider as a supporting fact. The proposed model agrees with existence of the different types of observed sources mechanisms.

In more general sense, the present study also documents, how subtle details of foci zone can be hypothesised from contemporary data. Such resolution of treated details is fully comparable with "big" earthquakes studies as e.g. (Jolivet et al., 2014).

Consecutive pronounced seismic swarms occurred in the West Bohemian region in years 2011, 2013, 2014 and 2017 - these data can be subject of similar approach, the conclusions can be compared and the hypotheses formulated here can be confronted. As these consecutive swarms occurred closely to the 2008 year swarm, we expect that under favourable circumstances the mapped/investigated fault area can be expanded up to $5 \times 12 \mathrm{~km}$ (while the presented study covers area of about $4 \times 4 \mathrm{~km})$.

\section{ACKNOWLEDGEMENT}

The authors are thankful to their colleagues V. Vavryčuk, T. Fischer, B. Růžek and P. Hrubcová who kindly provided results of their studies to us. We would also like to thank reviewers for their improving comments.

The work was supported by grant GAČR 1603950S P108.

\section{REFERENCES}

Aki, K. and Richards, P.G.: 1980, Quantitative Seismology. W. H. Freeman and Co., San Francisco.

Aki. K. and Richards, P.G.: 2009, Quantitative seismology 2nd. University Science Book, Sausalito.

Alexandrakis, C., Calò, M., Bouchaala, F. and Vavryčuk, V.: 2014, Velocity structure and the role of fluids in the West Bohemia Seismic Zone. Solid Earth, 5, 863872. DOI: $10.5194 / \mathrm{se}-5-863-2014$

Babuška, V., Plomerová, J. and Fischer, T.: 2007, Intraplate seismicity in the western Bohemian Massif (central Europe): A possible correlation with a paleoplate junction. J. Geodyn., 44, 149-159. DOI: $10.1016 /$ j.jog.2007.02.004

Babuška, V., Plomerová, J., and Vecsey, L.: 2010, Links between the structure of the mantle lithosphere and morphology of the Cheb Basin (Eger Rift, central Europe). Int. J. Earth Sci., 99, 1535-1544. DOI: $10.1007 / \mathrm{s} 00531-010-0531-4$

Babuška, V., Růžek, B. and Dolejš, D.: 2015, Origin of earthquake swarms in the western Bohemian Massif: Is the mantle $\mathrm{CO} 2$ degassing, followed by the Cheb Basin subsidence, an essential driving force? Tectonophysics, 668-669, 42-51. DOI: $10.1016 /$ j.tecto. 2015.12 .008

Bachura, M. and Fischer, T.: 2016, Detailed velocity ratio mapping during the aftershock sequence as a tool to monitor the fluid activity within the fault plane. Earth Planet. Sci. Lett., 453, 215-222. DOI: 10.1016/j.eps1.2016.08.017

Bankwitz, P., Schneider, G., Kämpf, H. and Bankwitz, E.: 2003, Structural characteristics of epicentral areas in Central Europe: study case Cheb Basin (Czech Republic). J. Geodyn., 35, 5-32. DOI: $10.1016 / \mathrm{S} 0264-3707(02) 00051-0$ 
Boatwright, J.: 1980, A spectral theory for circular seismic sources; simple estimates of source dimension, dynamic stress drop, and radiated seismic energy. Bull. Seismol. Soc. Am., 70, 1-27.

Bouchaala, F., Vavryčuk, V. and Fischer, T.: 2013, Accuracy of the master-event and double-difference locations: synthetic tests and application to seismicity in West Bohemia, Czech Republic. J. Seismol., 17, 841-859. DOI: $10.1007 / \mathrm{s} 10950-013-9357-4$

Čermáková, H. and Horálek, J.: 2015, The 2011 West Bohemia (Central Europe) earthquake swarm compared with the previous swarms of 2000 and 2008. J. Seismol., 19, 899-913. DOI: $10.1007 / \mathrm{s} 10950-015-9502-3$

Fischer, T. and Horálek, J.: 2005, Slip-generated patterns of swarm microearthquakes from West Bohemia/Vogtland (central Europe): Evidence of their triggering mechanism? J. Geophys. Res., 110, B05S21. DOI: 10.1029/2004JB003363

Fischer, T., Horálek, J., Hrubcová, P. et al.: 2014, Intracontinental earthquake swarms in West-Bohemia and Vogtland: A review. Tectonophysics, 611, 1-27. DOI: $10.1016 / j$.tecto.2013.11.001

Fischer, T., Horálek. J., Michálek, J. and Boušková, A.: 2010, The 2008 West Bohemia earthquake swarm in the light of the WEBNET network. J. Seismol., 14, 665-682. DOI: $10.1007 / \mathrm{s} 10950-010-9189-4$

Geissler, W.H., Kämpf, H., Kind, R. et al.: 2005, Seismic structure and location of a $\mathrm{CO} 2$ source in the upper mantle of the western Eger (Ohře) Rift, central Europe. Tectonics , 24, 5, TC5001. DOI: 10.1029/2004TC001672

Hainzl, S. and Fischer, T.: 2002, Indications for a successively triggered rupture growth underlying the 2000 earthquake swarm in Vogtland/NW Bohemia. J. Geophys. Res., 107, 2338. DOI: $10.1029 / 2002 J B 001865$

Hanks, T.C. and Kanamori, A.: 1979, A magnitude scale. J. Geophys. Res., 84, 2348-2350.

Hecht, L., Vigneresse, J.L. and Mortani, G.: 1997, Constraints on the origin of zonation of the granite complexes in the Fichtelgebirge (Germany and Czech Republic): evidence from a gravity and geochemical study. Geol. Rundschau, 86, S93-S109. DOI: 10.1007/PL00014669

Horálek, J., Š́lený, J., Fischer, T. et al.: 2000, Scenario of the January 1997 West Bohemia Earthquake Swarm. Stud. Geophys. Geod., 44, 491-521. DOI: $10.1023 / \mathrm{A}: 1021811600752$

Horálek, J., Š́lený, J. and Fischer, T.: 2002, Moment tensors of the January 1997 earthquake swarm in NW Bohemia (Czech Republic): double-couple vs. nondouble-couple events. Tectonophysics , 356, 65-85. DOI: 10.1016/S0040-1951(02)00377-3

Chum, J., Hruška. F., Zedník, J. and Laštovička, J.: 2012, Ionospheric disturbances (infrasound waves) over the Czech Republic excited by the 2011 Tohoku earthquake. J. Geophys. Res., 117, A08319. DOI: 10.1029/2012JA017767

Ihmlé, P.F. and Ruegg, J.-C.: 1997, Source tomography by simulated annealing using broad-band surface waves and geodetic data: application to the $\mathrm{Mw}=8.1$ Chile 1995 event. Geophys. J. Int., 131, 146-158. DOI: 10.1111/j.1365-246X.1997.tb00601.x

Jolivet, R., Duputel, Z., Riel, B. et al.: 2014, The 2013 Mw 7.7 Balochistan earthquake: Seismic potential of an accretionary wedge. Bull. Seismol. Soc. Am., 104, 1020-1030. DOI: $10.1785 / 0120130313$

Koláŕ, P.: 2015, Estimation of parameters of finite seismic source model for selected event of West Bohemia year
2008 seismic swarm - methodology improvement and data extension. J. Seismol., 19, 935-947.

DOI: $10.1007 / \mathrm{s} 10950-015-9504-1$

Kolář, P.: 2013, Tool for finite seismic source parameters determination - stopping phases method, ver.2. In: Tech. Comput. Prague 2013.

http://www2.humusoft.cz/www/papers/tcp13/034_kolar.pdf. Accessed 17 Jan 2018

Kolář, P. and Růžek, B.: 2012, Finite seismic source parameters inferred from stopping phases for selected events of West Bohemia 2000 swarm. Acta. Geodyn. Geomater., 9, 435-447.

Kolář, P. and Růžek, B.: 2015, Estimation of finite seismic source parameters for selected events of the West Bohemia year 2008 seismic swarm. J. Seismol., 19, 403-421. DOI: 10.1007/s10950-014-9474-8

Kolář, P., Růžek, B., Boušková, A. and Horálek, J.: 2011, Visualisation of the fault slip connected with the West Bohemia earthquake swarms. Acta Geodyn. Geomater., 8, 169-187.

Liu, P. and Archuleta, R.J.: 2004, A new nonlinear finite fault inversion with three-dimensional Green's functions: Application to the 1989 Loma Prieta, California, earthquake. J. Geophys. Res., Solid Earth, 109, B2. DOI: 10.1029/2003JB002625

Mousavi, S., Bauer, K., Korn, M. and Hejrani, B.: 2015, Seismic tomography reveals a mid-crustal intrusive body, fluid pathways and their relation to the earthquake swarms in West Bohemia/Vogtland. Geophys. J. Int., 203, 1113-1127. DOI: $10.1093 /$ gji $/$ ggv338

Mrlina. J., Kämpf, H., Kroner, C. et al.: 2009, Discovery of the first Quaternary maar in the Bohemian Massif, Central Europe, based on combined geophysical and geological surveys. J. Volcanol. Geotherm. Res., 182, 97-112. DOI: 10.1016/j.jvolgeores.2009.01.027

Novotný, O., Málek, J. and Boušková, A.: 2016, Wadati method as a simple tool to study seismically active fault zones: a case study from the WestBohemia/Vogtland region, central Europe. Stud. Geophys. Geod., 60, 2, 248-267.

DOI: $10.1007 / \mathrm{s} 11200-015-1206-1$

Růžek, B. and Horálek, J.: 2013, Three-dimensional seismic velocity model of the West Bohemia/Vogtland seismoactive region. Geophys. J. Int., 195, 12511266. DOI: $10.1093 /$ gji/ggt295

Stein, S. and Wysession, M.: 2003, An Introduction to Seismology, Earthquakes and Earth Structure. John Wiley \& Sons.

Vavryčuk, V., Adamová, P., Doubravová, J. and Jakoubková, H.: 2017, Moment tensor inversion based on the principal component analysis of waveforms: Method and application to microearthquakes in West Bohemia, Czech Republic. Seismol. Res. Lett., 88, 5, 1303-1315. DOI: 10.1785/0220170027

Vavryčuk, V., Bouchaala, F. and Fischer, T.: 2013, Highresolution fault image from accurate locations and focal mechanisms of the 2008 swarm earthquakes in West Bohemia, Czech Republic. Tectonophysics, 590, 189-195. DOI: $10.1016 /$ j.tecto.2013.01.025

(2008) (special issue devotes to West Bohemia topics - part 1). Stud. Geophys. Geod. 52(4):

(2009) (special issue devotes to West Bohemia topics - part 2). Stud. Geophys. Geod. 53(3):

wwwWEBNET. http://www.ig.cas.cz/en/map-webnetstations. Accessed 17 Jan 2018

wwwFDSN: WB: West Bohemia Local Seismic Network. DOI: $10.7914 / \mathrm{SN} / \mathrm{WB}$.

http://www.fdsn.org/network/detailWB. Accessed 17 Jan 2018 


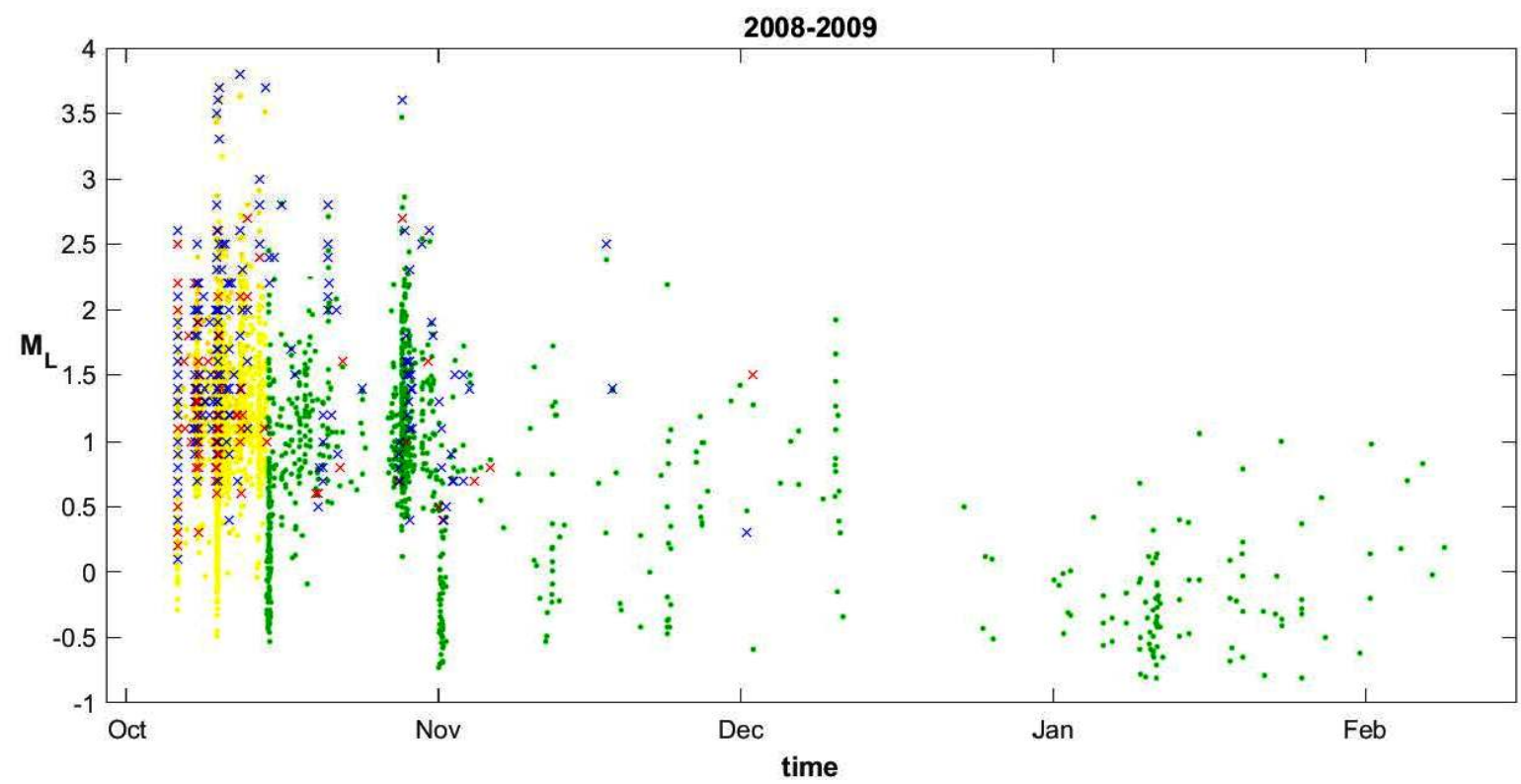

Fig. 2a Time distribution of the swarm with its individual phases: the first two swarm phases are marked by yellow dots; the rest by green dots. The selected events processed in the study are marked by crosses: events with principal source mechanisms by blue colour, the complementary ones by red colour.

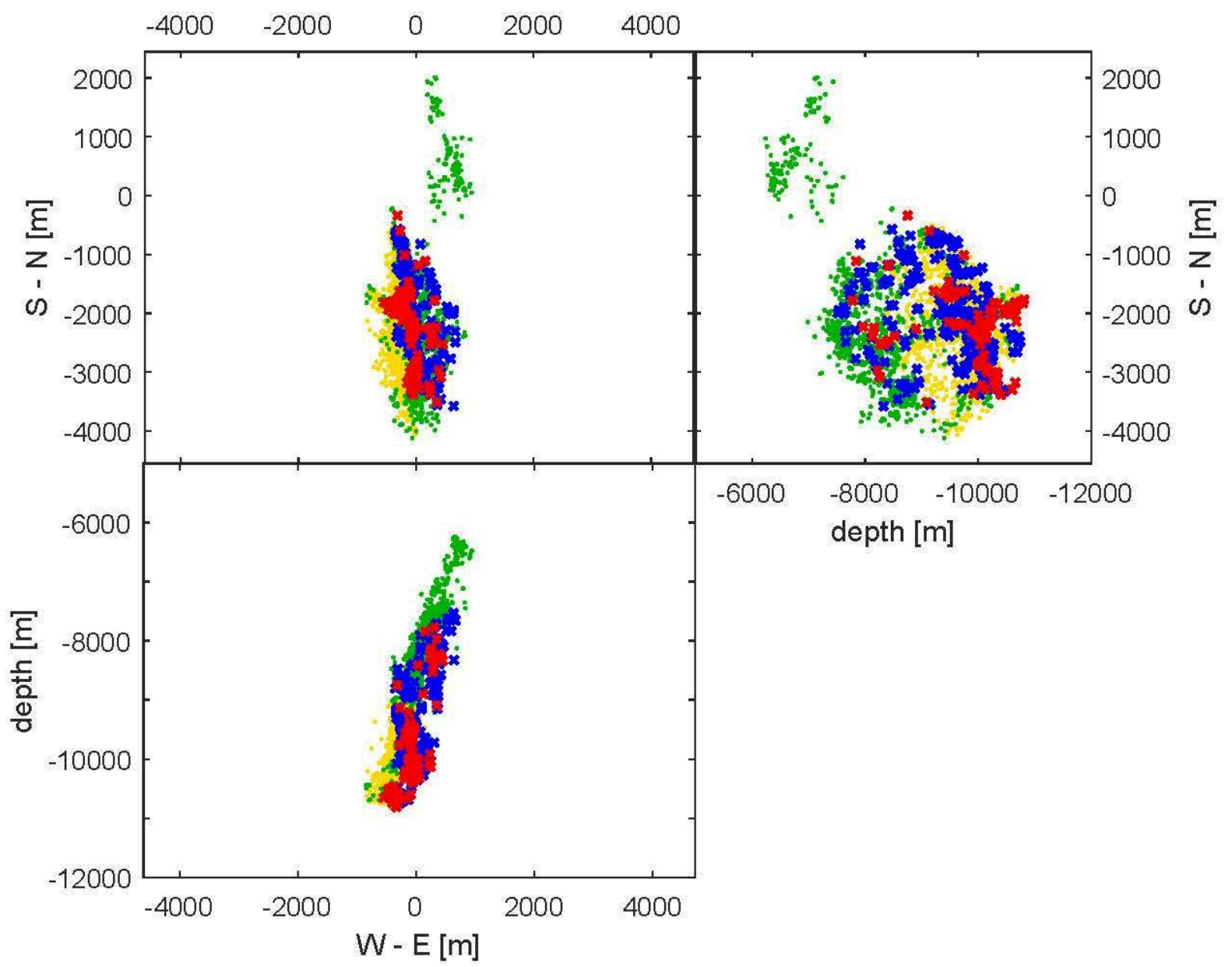

Fig. 2b Spatial distribution of the swarm hypocentres. Upper left is a horizontal projection, upper right is a vertical projection seen from east, lower is a vertical projection seen from south. The meaning of the colours is the same as in Figure 2a; origin of the coordinates is in station Nový Kostel (NKC). The figure documents prevalent 2D NS-vertically oriented distribution of processed event foci. 


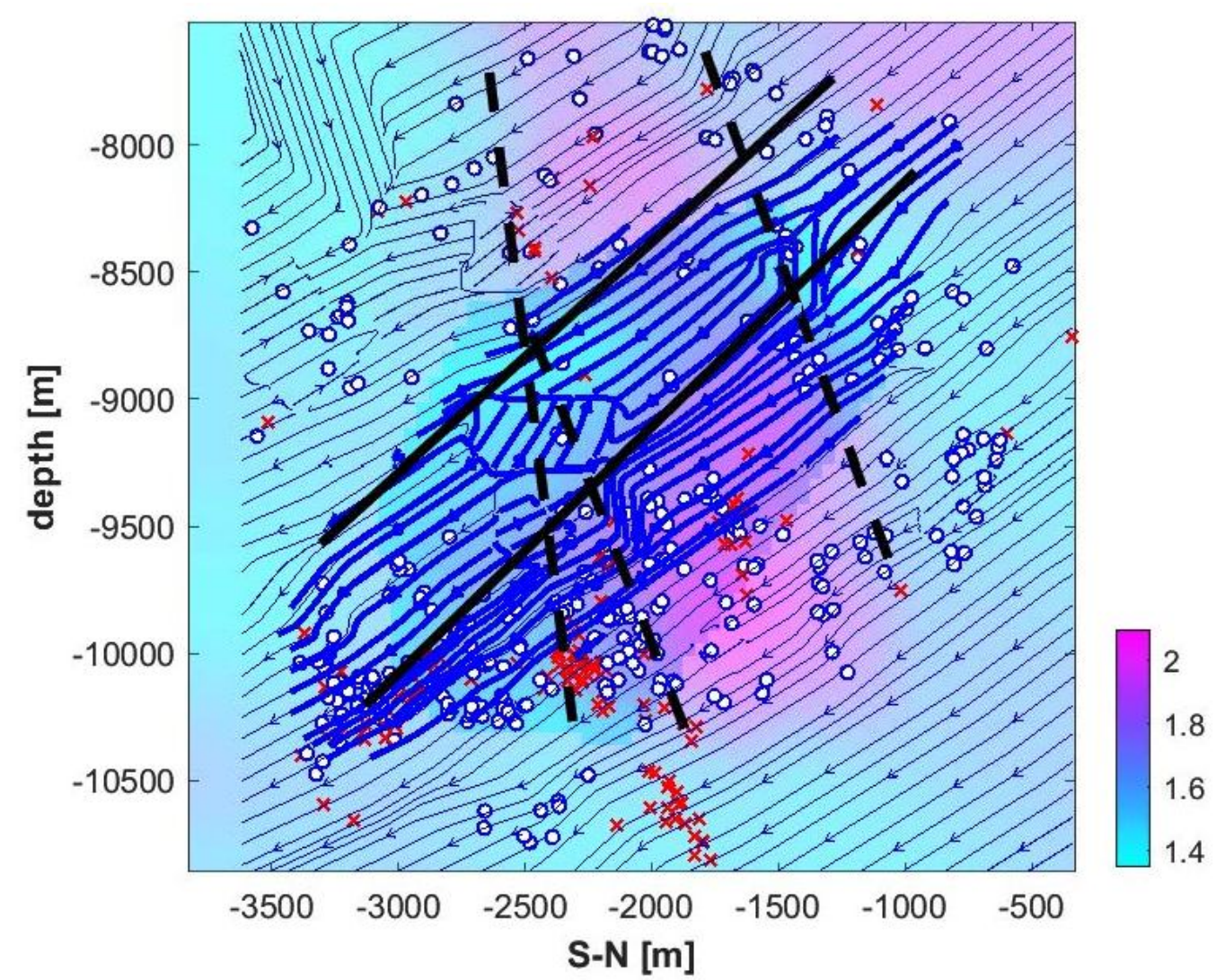

Fig. 7 2D vertical N-S slip. The same as in Figure 5, but in addition slip for complementary events is plotted in the form of coloured areas (relative scale is used). The extrapolated values are marked by thin lines or more transparent colours, the interpolated then by thick lines or less transparent colour. We interpret two inclined boundaries (full black lines) and three sub-vertical boundaries (dashed black lines).

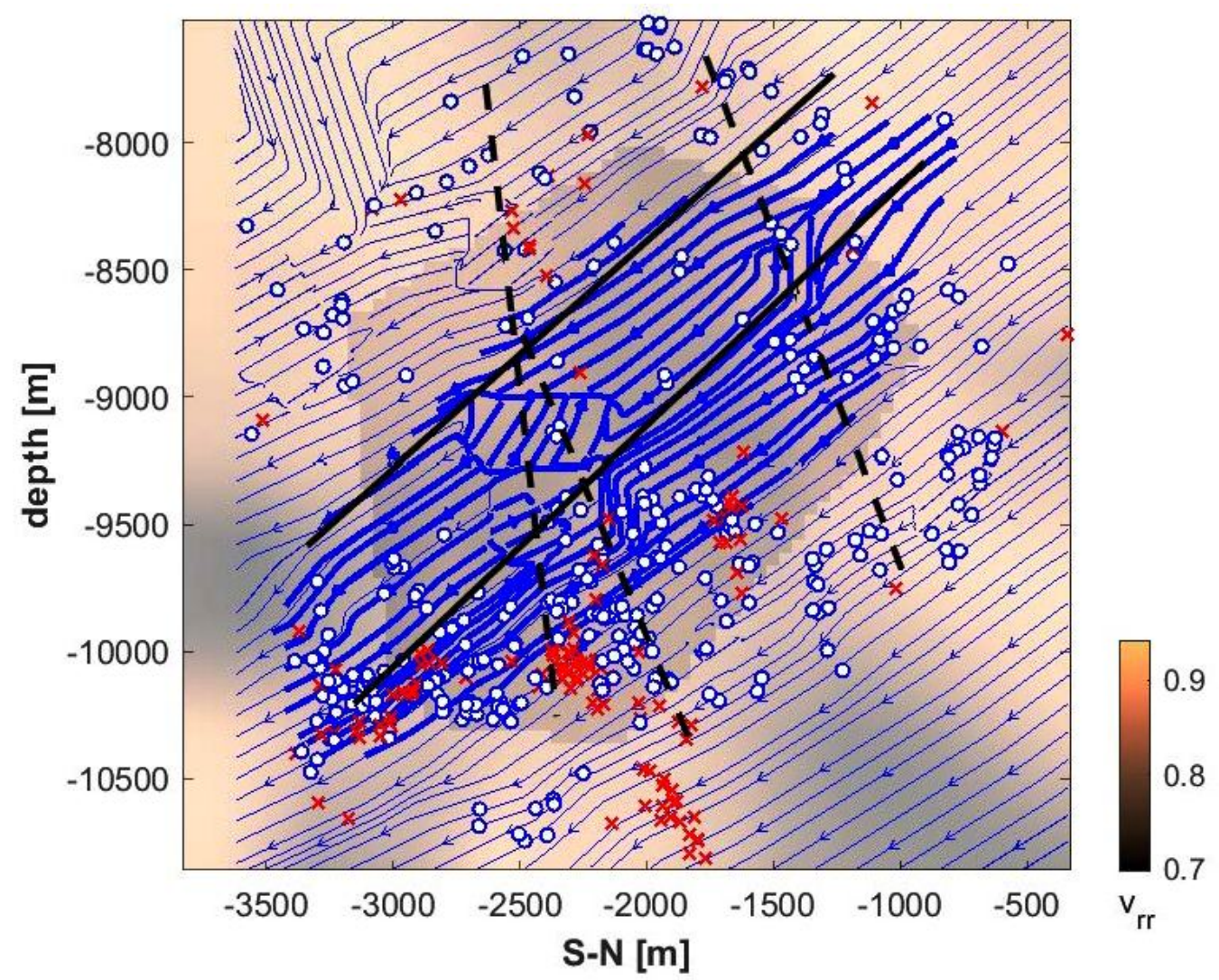

Fig. $112 \mathrm{D}$ vertical N-S slice of relative rupture velocity $v_{r r}$ for complementary events (marked by colour scale); principal events slip flow is added (the same as in Figure 5). Similar boundaries as in slip image can be interpreted (black lines). 

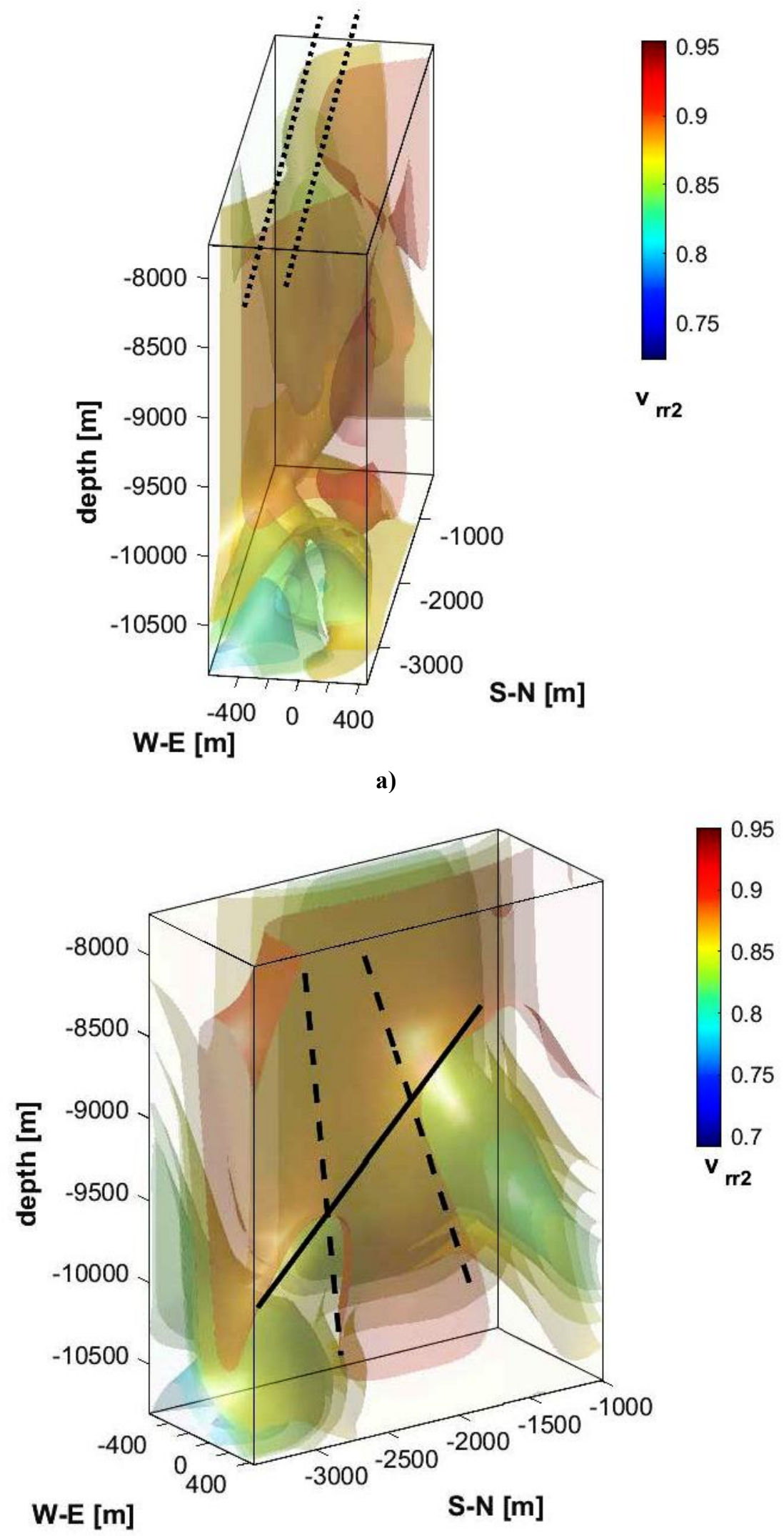

b)

Fig. 12 3D distribution of relative rupture velocity $v_{r r}$ (izoplanes of constant values) for complementary events (the available data are extrapolated towards the cube edges). In Figure 12a are used all complementary events. Vertical parallel plane boundaries (their orientation is marked by dotted lines) with undulation can be interpreted. In Figure $12 \mathrm{~b}$ there are used only stronger complementary events $\left(\mathrm{M}_{1}>0.8\right.$, i.e. 79 from 130 events in this case). We interpret again similar boundaries as in Figures 7 and 11; for more detailed discussion see the text. The coordinate origin is in NKC station. 